\title{
Sexualidade e reprodução: discutindo gênero e integralidade na Atenção Primária à Saúde
}

\author{
| ${ }^{1}$ Thiago Félix Pinheiro, ${ }^{2}$ Márcia Thereza Couto |
}

Resumo: A noção de integralidade, estabelecida como princípio de açôes e políticas no SUS, tem norteado diversas discussōes no campo da Saúde Coletiva. Na direção do debate integralidade-gênero, este artigo explora a (des) articulação entre sexualidade e reprodução na assistência prestada a homens e mulheres em serviços da Atenção Primária à Saúde (APS). Para tanto, faz uma dupla apropriação da ideia de relação, abordando homensmulheres e sexualidade-reprodução como intrinsecamente relacionais. $\mathrm{O}$ estudo é recorte de pesquisa multicêntrica, de natureza qualitativa, voltada à investigação da relação entre homens e serviços de APS. Utiliza dados provenientes da observação etnográfica de quatro Unidades de Saúde da Família (USF), localizadas nos estados do Rio Grande do Norte e Pernambuco. Os resultados apontam para desarticulações na estrutura organizacional das USF que comprometem a efetivação de uma atenção integral à saúde de homens e de mulheres. Nessa direção, os discursos e práticas dos/as profissionais de saúde (re)produzem fragmentações na assistência, sobretudo em função da associação homens-sexualidade e mulheres-reprodução. Tomando-se a integralidade como horizonte, aponta-se para a necessidade de uma (re)articulação entre sexualidade e reprodução que, ao invés de subjugar uma a outra, possibilite reconhecer as diversas expressões dessas esferas nas vivências concretas de homens e mulheres, assim como o diálogo entre diferentes intervenções relacionadas à saúde sexual e à saúde reprodutiva a partir de pontos de convergência possíveis.

> Palavras-chave: Atenção integral à saúde; saúde reprodutiva; sexualidade; Atenção Primária à Saúde; gênero.
1 Programa de Pós-Graduação em Medicina Preventiva, Faculdade de Medicina, Universidade de São Paulo (FMUSP). Endereço eletrônico: thiagopinheiro@hotmail.com

2 Departamento de Medicina Preventiva da FMUSP. Endereço eletrônico: marthet@usp.br

Recebido em: 12/07/2012. Aprovado em: 20/02/2013. 


\section{Integralidade e gênero na assistência à saúde}

Sob o título de integralidade, importantes questôes têm sido apresentadas e debatidas no campo da Saúde Coletiva nas últimas três décadas no Brasil. Nessa direção, recorremos a tal perspectiva para discutir gênero e suas articulaçóes com sexualidade e reprodução no contexto da Atenção Primária à Saúde (APS) e, em especial, na Estratégia Saúde da Família (ESF) que, desde 2006, com a publicação da Política Nacional de Atenção Básica (BRASIL, 2006), foi reafirmada como a principal estratégia para a organização da APS.

A ideia de integralidade é oriunda do movimento designado "medicina integral", cuja origem remete às discussões sobre o ensino médico nos Estados Unidos, nas quais marcava uma crítica à fragmentação da prática médica, cada vez mais inserida num sistema de especialidades, e ao reducionismo da atuação médica que recortava analiticamente os pacientes, reduzindo-os ao aparelho/ sistema biológico supostamente produtor de sofrimento. No Brasil, essa noção esteve associada à medicina preventiva, à saúde coletiva e, logo, à reforma sanitária. Em tais movimentos, foi fundamental para a unificação da assistência médica e da saúde pública, vindo a se tornar princípio e diretriz para a organização do Sistema Único de Saúde (SUS) (MATTOS, 2001).

Teixeira (2003) ressalta que os diversos sentidos empregados à noção de integralidade no campo da saúde se articulam sempre em torno de um núcleo semântico simples e geral: a qualidade de integral como equivalente a estar todo, inteiro, completo. Dessa forma, as diversas compreensóes da noção dependeriam fundamentalmente do que os diferentes projetos tecnopolíticos no campo pretendem integrar, tornar inteiro.

A polissemia da noção de integralidade e a abrangência do debate a esse respeito certamente extrapolam uma análise da assistência relacionada à saúde sexual e à saúde reprodutiva em serviços da APS, na modalidade ESF, a partir da perspectiva de gênero. Esse recorte, no entanto, nos parece fértil e, embora não seja uma novidade como articulação teórica, ainda parece pouco explorado. Para realizar essa articulação, tomamos então como referência os sentidos atribuídos por Mattos (2001) ao princípio de integralidade: um valor a ser sustentado e defendido nas práticas dos profissionais de saúde, na direção da boa prática; atributos da organização dos serviços de saúde; e respostas governamentais aos problemas de saúde. 
Especificamente em relação à última dessas dimensões de sentido, lembramos que o diálogo com a perspectiva de gênero fez parte da inserção da noção de integralidade no âmbito das políticas públicas no Brasil, inaugurando a acepção do termo como atributo das respostas governamentais a problemas de saúde de grupos populacionais específicos (MATTOS, 2003). Propostas como o Programa de Assistência Integral à Saúde da Mulher (PAISM), reconfigurado e ampliado como Política Nacional de Atenção Integral à Saúde da Mulher (PNAISM), e a recente Política Nacional de Atenção Integral à Saúde do Homem (PNAISH), que legitimam e regulamentam a construção de ações em saúde conformadas pela noção de gênero, fundamentam-se no horizonte de uma atenção integral em saúde (BRASIL, 2004; 2009).

Adicionalmente, recorremos à noção de relação, conforme discutida por Joan Scott (1986). Entre outros argumentos, a autora assinalou a crítica feita por parte de feministas estadunidenses à produção de estudos que se centravam nas mulheres de forma estreita e isolada, afirmando que nenhuma compreensão das mulheres nem dos homens poderia ser elaborada por meio de estudo inteiramente separado. Assim, foi introduzida no vocabulário analítico de gênero a dimensão relacional da categoria, de acordo com a qual as mulheres e os homens são definidos em termos recíprocos. A partir desse referencial, atentamos para o fato histórico de que a apropriação da perspectiva de gênero no âmbito das práticas e das políticas de saúde resvala em desarticulações, sobretudo no que diz respeito à compreensão relacional do binômio homem-mulher.

De um lado, a história da saúde da mulher está atrelada ao desenvolvimento da medicina e da produção da tecnologia médica voltada para o corpo feminino, que foram responsáveis por um avanço nas condições de saúde e sobrevivência de mulheres e crianças, solucionando problemas cruciais da reprodução social (VIEIRA, 2002). Ao mesmo tempo, essa história é marcada pela manutenção do controle médico, sobretudo ginecológico, sobre as mulheres (ROHDEN, 2001), tal como apontado na crítica feita pelo movimento feminista.

No Brasil, a reivindicação do movimento de mulheres a respeito da necessidade de se superar o reducionismo que circunscrevia a abordagem dos problemas de saúde das mulheres, alheio aos contextos culturais e às diversas formas de dominação que conferiam especificidades a seu adoecimento, influenciou diretamente a elaboração do PAISM. A definição das mulheres como população- 
alvo prioritária de ações em saúde nesse programa assinala uma ruptura com a concepção que marcava sua presença no grupo materno-infantil (MATTOS, 2003). Ao longo das últimas décadas, tais ações têm representado a tentativa de efetivar uma abordagem integral da saúde das mulheres, trazendo para a assistência questóes que extrapolam a saúde reprodutiva, tais como violência de gênero e climatério, entre outras.

No entanto, embora a formulação da assistência como atenção integral, a partir do PAISM, fornecesse as bases para a articulação entre diferentes temas da saúde da mulher, dentre os quais se destacavam a reprodução e a sexualidade, tal proposta não se efetivou plenamente. A saúde sexual, por exemplo, não conseguiu se desenvolver tanto quando a saúde reprodutiva (SCHRAIBER, 2008). Nesse sentido, mesmo diante da tentativa de ultrapassar o reducionismo da mulher a mamas, útero e gestação, a principal referência das práticas em saúde para mulheres parece ainda ser a diferenciação do corpo feminino como um corpo que reproduz (MEDEIROS; GUARESCHI, 2009).

Em virtude dessa histórica inserção das mulheres nos serviços da APS, elas representam melhor do que os homens a clientela atendida, tanto em termos de frequência, quanto de familiaridade com o espaço e a lógica de organização; mostram-se mais adaptadas aos moldes de funcionamento do serviço e mais à vontade na comunicação com os profissionais, no uso do espaço e nas formas de interação (COUTO et al., 2010).

A proposta de estruturação de uma atenção integral à saúde do homem, que pode ser discutida à luz da PNAISH, surge como resposta à evidência da menor presença dos homens no contexto da assistência, em especial nos serviços de APS; que se agrava no contraste com os índices de mortalidade, nos quais se destacam sobretaxas de óbito de homens para todas as causas de morte e em praticamente todas as faixas etárias (LAURTENTI; MELO JORGE; GOTLIEB, 2005). Nesse sentido, um dos desafios que a implantação de ações em saúde do homem tem a enfrentar é a própria inserção dos homens nos serviços da APS. A literatura sobre o tema tem apontado que essa inserção esbarra em diversas dificuldades, configuradas pelas características culturais da construção das masculinidades, que moldam as formas dos homens lidarem com a saúde (COURTENAY, 2000); pela atuação dos profissionais de saúde, que (re)produzem concepções de gênero, como a ideia de que o corpo masculino é um lócus do não-cuidado 
(MACHIN et al., 2011); e pela estruturação dos serviços de saúde, onde podemos identificar uma tendência à invisibilidade dos homens como alvo de intervenção em saúde, como usuários que têm dificuldade para acessar os serviços ou para serem acolhidos com suas demandas e como potenciais sujeitos de cuidado (FIGUEIREDO; SCHRAIBER, 2011; COUTO et al., 2010).

Em sua fase de elaboração, a PNAISH despertou a crítica de pesquisadores da área devido ao foco dado à sexualidade, reduzida, nos termos da medicalização, à assistência à disfunção erétil (CARRARA; RUSSO; FARO, 2009). Esse problema de saúde tem sido central nas discussões sobre saúde do homem mesmo antes da política, ao lado de outros problemas relativos à sexualidade, como a infecção por HIV e a andropausa ou climatério masculino (AQUINO, 2005).

Em paralelo, os documentos da política chamam a atenção pela pouca ênfase dada às questôes de saúde reprodutiva e à paternidade (MEDRADO et al., 2011). Essa preocupação está relacionada com a incipiente inclusão dos homens nas discussões reprodutivas, realizada de forma instrumental, na qual eles ocupam não o lugar de sujeitos que se reproduzem e podem regular sua fecundidade, mas o papel daqueles que apoiam ou dificultam as decisões de suas parceiras (FIGUEROA-PEREA, 1998).

Como podemos ver, a desarticulação entre a atenção oferecida à saúde dos homens e à saúde das mulheres, embora não se esgote nos aspectos apontados, pode ser delineada em função da assistência oferecida às esferas da sexualidade e da reprodução.

Nessas esferas compreendemos também ser legítima a aplicação da dimensão relacional, considerando a estreita relação que a construção social das mesmas mantém entre si e com o referencial cultural de gênero. Como lembram Villela e Arilha (2003), uma vez que a relação sexual entre homem e mulher pode gerar outros seres, parte das normas relacionadas às práticas sexuais está atrelada ao modo como cada cultura lida com a reprodução.

No contexto dos serviços de APS, parece operar uma desarticulação entre essas esferas, que, de um lado, pouco efetiva a crítica feminista contra a redução da mulher ou da sexualidade à finalidade reprodutiva e, de outro, dificulta o aproveitamento das possibilidades de ação propiciadas pelos pontos de contato entre a saúde sexual e a saúde reprodutiva. Assim, a sexualidade e a reprodução se polarizam na medida em que se desarticula o par masculino e feminino da 
configuração cultural de gênero, conforme expresso no questionamento lançado por Leal e Boff (1996): Será que a sexualidade está para o homem assim como a reprodução está para a mulher?

Nestes termos, o presente artigo explora a (des) articulação entre sexualidade e reprodução na assistência prestada a homens e mulheres em serviços de APS. A dupla apropriação que fazemos da ideia de relação - homens-mulheres e sexualidade-reprodução - nos remete à noção de integralidade, em sua acepção primeira de "tornar inteiro", uma vez que nosso argumento segue na direção de conectar, articular, tornar dialógico o que compreendemos como intrinsecamente relacional.

\section{Percurso metodológico}

As bases empíricas da reflexão aqui proposta derivam de um recorte de pesquisa multicêntrica voltada à investigação da relação entre homens e serviços de APS em cidades de quatro estados brasileiros (PE, RJ, RN e SP), realizada no período de março de 2007 a março de 2008. O projeto foi aprovado pelo Comitê Nacional de Ética em Pesquisa e pelos respectivos comitês das instituições acadêmicas parceiras em cada estado, bem como pelas Secretarias de Saúde dos municípios participantes ${ }^{1}$.

Foram investigados oito serviços, amostrados por conveniência, considerando tempo de funcionamento de pelo menos dez anos; equipe multiprofissional de saúde, em atividade há pelo menos dois anos; e volume de demanda igual ou maior a mil atendimentos por mês. Os serviços apresentam características em comum, sobretudo no que diz respeito à configuração da APS como porta de entrada para a assistência no SUS.

Priorizamos para este estudo os serviços cuja estrutura e organização da assistência são estabelecidas nos moldes da ESF. Dessa forma, optamos pelo recorte da análise do cotidiano de quatro Unidades de Saúde da Família (USF) - duas localizadas em Natal/RN, uma em Recife/PE e uma em Olinda/PE. Esses serviços, doravante denominados RN1, RN2, PE1 e PE2, apresentam estruturas físicas e organizacionais semelhantes e, por esse motivo, são analisadas aqui de forma conjunta.

A pesquisa multicêntrica, de natureza qualitativa, se apoiou na triangulação de métodos, incluindo diferentes técnicas de coleta de dados, dentre as quais 
destacamos para este estudo a observação etnográfica dos serviços. Essa técnica fundamenta-se pela perspectiva etnográfica, que tem longa tradição na Antropologia, e dispõe, como pressuposto fundante, a interpretação dos aspectos simbólicos e culturais nos contextos sociais em que ocorrem (GEERTZ, 1997). Constituem as bases para essa análise as descriçõos de diários de campo, produzidas por duplas pesquisadores/as com habilidade em etnografia e supervisionados pelos coordenadores da pesquisa nos estados, ao longo de três meses em cada um dos serviços, nos períodos da manhã e da tarde, respeitando o funcionamento semanal das UBS e a totalidade das atividades assistenciais.

No diz respeito às temáticas que foram alvo da observação etnográfica, neste trabalho são destacadas a reprodução e a sexualidade, tendo como pano de fundo a atenção dirigida a homens e a mulheres no contexto assistencial. Inicialmente, analisam-se a presença e a configuração de ações voltadas à saúde sexual e à saúde reprodutiva, assim como a emergência de questôes relacionadas a essas temáticas no contexto das atividades realizadas. Na sequência, são analisadas as demandas e necessidades de saúde apresentadas pelos/as usuários/as a esse respeito e as respostas assistenciais oferecidas (ou não) pelos serviços.

$\mathrm{O}$ trajeto analítico-interpretativo foi orientado pela hermenêutica filosófica, segundo a qual a compreensão ocorre como interpretação, na qual está implicado o sujeito que interpreta. Assim, o encontro entre o sujeito que busca conhecimento e o sujeito que informa é mais bem definido como um diálogo, em que, em vez de se alcançar o significado contido no fenômeno, negocia-se tal significado. $\mathrm{O}$ compreender e o interpretar consistem sempre em participar de um diálogo em que os horizontes se fundem (AYRES, 2008).

A fim de ilustrar e clarificar os resultados apontados, apresentaremos trechos dos diários de campo provenientes da observação direta ou de considerações dos pesquisadores de campo.

\section{Mulheres e reprodução $\mathrm{x}$ homens e sexualidade: desarticulações na estrutura das USF}

As quatro UFS pesquisadas localizam-se em regiōes pobres e com diversos problemas sociais e de infraestrutura, compreendidas como periferias de centros urbanos de dois estados do Nordeste brasileiro. Seus/suas usuários/as são residentes dessas localidades, uma vez que cada USF tem como responsabilidade 
sanitária determinada área no entorno da respectiva unidade. Dessa forma, essas pessoas detêm, em geral, pouco poder aquisitivo e utilizam predominantemente os serviços públicos de saúde.

A estrutura dos serviços é definida de acordo com a ESF e busca refletir, na direção apontada por Schraiber (2005), o encontro de certa tradição da atenção básica na repartição dos espaços e organização das atividades com as inovações implantadas pela estratégia, como as açôes na comunidade e nos domicílios, maior articulação entre as necessidades detectadas na comunidade e os atendimentos, ênfase na prevenção e na promoção da saúde e um planejamento mais participativo da assistência.

Em termos de estrutura física, os serviços contam com espaço suficiente para a realização de suas atividades: atendimentos ambulatoriais, procedimentos de enfermagem (curativos, vacina e pré-consulta), reuniões e atividades em grupo, farmácia, além das atividades externas (visitas domiciliárias e atividades de assistência e educação em saúde em instituiçõos como escolas e fábricas). As equipes multiprofissionais são compostas por médico/a, enfermeiro/a, auxiliar de enfermagem, odontólogo/a, auxiliar de consultório dentário e grupo de agentes comunitários de saúde (ACS). As unidades RN1 e PE1 contam com três equipes de saúde da família, enquanto RN2 e PE2 dispõem de duas. Além das equipes nucleares, algumas unidades dispõem de outros profissionais de saúde como técnico em exames laboratoriais (RN1), técnica em higiene dental (PE1 e PE2), agentes de saúde ambiental (PE1), psicóloga, assistente social e fisioterapeutas (RN2).

No cotidiano desses serviços, é constante a predominância das mulheres, tanto na composição das equipes quanto do público atendido, fato que reforça o caráter feminilizado do ambiente dos serviços, já apontado na literatura (FIGUEIREDO; SCHRAIBER, 2011; GOMES et al., 2011).

Nas observações do fluxo de funcionamento, pudemos mapear alguns trajetos percorridos por homens e mulheres e, a partir disso, compreender as vias de acesso em função da variável sexo da população assistida. Nesse sentido, notamos a participação de homens e mulheres em atendimentos ambulatoriais voltados para o acompanhamento de doenças crônicas (sobretudo diabetes e hipertensão arterial) ou abertos a demandas espontâneas, assim como em atividades educativas em grupo, atendimentos odontológicos, procedimentos de enfermagem e 
dispensação de medicamentos na farmácia. Embora seja nítida a predominância

de mulheres nessas atividades, a presença de homens é considerável, de modo que a discrepância observada em relação à presença de homens e mulheres nos serviços não parece estar tão atrelada à participação em tais atividades.

A UBS é um espaço marcadamente feminino, pois, em todas as atividades, elas são a maioria da clientela. Mas os homens aos poucos vão conquistando espaço na unidade. O grupo de HIPERDIA [hipertensão e diabetes] possui grande concentração de homens. Também os encontramos nas consultas para adultos, pegando remédio ou resultados de exames, preservativos, acompanhando crianças e esposas, solicitando atestado, aferindo pressão, fazendo curativos, solicitando encaminhamento de exames e, raramente, participando do planejamento familiar (PE1).

De outro lado, no rol das atividades oferecidas pelas unidades, é marcado o direcionamento de parte delas para o cuidado com a saúde das mulheres. Trata-se de um conjunto de atividades nitidamente voltadas à saúde reprodutiva e realizadas praticamente sem a presença de homens. Abrangem atendimentos ambulatoriais de assistência pré-natal e grupos de planejamento familiar. A despeito das críticas feitas pelo movimento feminista e das tentativas de inserção dos homens nas discussões e decisões acerca do planejamento familiar (BRASIL, 2004), reproduz-se, nos serviços pesquisados, a concepção de que a reprodução é uma esfera exclusivamente feminina.

A enfermeira ressaltou que seus planejamentos [familiares] sempre foram lotados e que a presença masculina é praticamente nula (PE1).

De forma semelhante ao pré-natal, o planejamento familiar é direcionado às mulheres, embora, como dizem as enfermeiras, seja "aberto aos homens". Elas defendem que os homens deveriam ir às consultas, mas não noticiamos nenhuma atitude de convite ou incentivo à presença dos mesmos. Em contrapartida, as mulheres que procuram outros atendimentos são conduzidas a discutir a reprodução no planejamento (RN1).

Tais atividades demarcam concretamente um espaço para atendimento das mulheres na agenda dos serviços, o que contrasta com a ausência de um espaço equivalente para atendimento com homens. A realização da pesquisa é anterior à implantação das ações orientadas pela PNAISH e, nesse cenário, nenhuma atividade sistemática dirigida aos homens usuários era encontrada em tais serviços, apenas algumas iniciativas isoladas e pontuais.

Essa discrepância pode ser observada, em especial, na atenção dada às infecções sexualmente transmissíveis (IST). Do conjunto de atividades voltadas à saúde da mulher, isto é, procedimentos de planejamento familiar e pré-natais, fazem parte 
atendimentos para realização continuada de exame preventivo de câncer de colo uterino, nos quais, eventualmente, são identificadas IST. Assim, a investigação dessas infecçōes guarda forte conotação de assistência à saúde reprodutiva. Após o diagnóstico, essas infecções costumam ser tratadas na própria UBS.

De modo diferente, os usuários não contam com essa investigação sistemática de IST. Quando identificam sinais de uma possível IST e, a despeito da resistência em expor demandas desse tipo, buscam atendimento, costumam ser encaminhados pelos profissionais das USF a serviços de atenção secundária para tratamento de tais enfermidades. Dessa forma, as IST das mulheres são assumidas como responsabilidades dos serviços de APS, enquanto as dos homens são compreendidas como alçada da assistência especializada.

A ênfase na associação mulher-reprodução também é encontrada nas visitas domiciliares, uma vez que, nessa atividade, destacam-se o registro e o acompanhamento das gravidezes e do período pós-parto, em contraste com os demais motivos de visita, em geral demandas relacionadas à identificação de situaçôes de risco epidemiológico e de idosos/as com doenças crônicas e impossibilitados/as de locomoção até as unidades.

$\mathrm{Na}$ distribuição de camisinhas, cuja discussão aprofundamos em outro artigo (PINHEIRO; COUTO, 2012), notamos uma polarização em função das esferas em discussão e do sexo da clientela. Existe uma dispensação livre na farmácia das unidades, disponível aos/às usuários/as a partir da busca espontânea. Em alguns casos, há o estímulo dos profissionais para essa busca ou uma distribuição de camisinhas em atividades externas. Nesses casos, há uma predominância de homens em tal atividade e a camisinha tem significado de prevenção de IST/AIDS. Ela é distribuída com pouco ou nenhum trabalho de orientação, sem abertura de prontuário e quase sempre sem se estimular a ampliação do vínculo usuário-serviço.

Por outro lado, as usuárias costumam receber camisinhas mediante a participação nas atividades de planejamento familiar. Aqui, a camisinha assume o significado de contraceptivo e sua distribuição ocorre em função de um vínculo estabelecido entre as usuárias e o serviço.

[Em visita domiciliária], a enfermeira lembrou à mãe que já era hora de pensar em um método contraceptivo e disse para a mulher conversar com o marido e decidir: "Na Unidade temos alguns métodos que você pode adotar. Lá nós temos camisinha, mini pílula e injeção, mas se você preferir pode usar a televisão (risos). Você é quem sabe o 
que quer usar. Converse com o seu parceiro e vá lá no dia do planejamento familiar

falar comigo" (RN1).

O primeiro procedimento do planejamento familiar é a entrega de senhas pela ACS para que haja ordem na entrega de camisinhas, anticoncepcionais e consulta com a enfermeira. [...] A mulher é chamada e recebe dez camisinhas, uma cartela de anticoncepcional e, se tiver algum exame para mostrar ou alguma dúvida, fala com a enfermeira. (PE1).

De forma similar, Schraiber (2005) identificou, em 12 equipes do Programa Saúde da Família (PSF) de Recife, que a abordagem à sexualidade com as mulheres está sempre subjacente e mascarada pela questão da contracepção. Além disso, nesse contexto, a sexualidade é objeto de julgamento moral e da disciplina.

A polarização mulher-reprodução $\mathrm{x}$ homem-sexualidade na estrutura organizacional das USF mostra que, além da desarticulação entre esses elementos, há a configuração de algumas iniquidades. Nesse sentido, as mulheres têm mais vias de acesso aos serviços e à assistência do que os homens, o que não significa que o acesso das usuárias (assim como o dos usuários) não seja cerceado por diversos limites, entre os quais estão aqueles operados pelas reduções da lógica biomédica. Da mesma forma, a sexualidade está menos inserida do que a reprodução na organização das atividades, parece ser menos legítima ao contexto da saúde da família.

\section{Fragmentos da assistência: desarticulações nos discursos e nas práticas dos/as profissionais das USF}

De modo geral, os discursos dos/as profissionais e as práticas assistenciais observadas espelham certo modo de operar o trabalho em saúde e de organizar a assistência centrado no exercício hegemônico de uma clínica pautada em atos prescritivos e na produção de procedimentos, em detrimento de uma clínica, segundo a proposição de Merhy (2004), como exercício ampliado de diferentes profissionais em relação entre si e com os/as usuários/as. Nesse sentido, a influência da estruturação tradicional do serviço - que, como assinalado, abre mais "espaços assistenciais" para as mulheres do que para os homens - é um dos primeiros aspectos que merecem ser destacados na conformação do desempenho do trabalho e no acolhimento destinado a usuários e usuárias. $\mathrm{O}$ relato a seguir explora esta dimensão: 
Observei em vários atendimentos que o médico age de forma diferente para com homens e mulheres. As consultas das mulheres são mais detalhadas, perguntam-se mais coisas sobre sua vida, principalmente sobre gestação, prevenção. Noto que o médico é mais cuidadoso com elas. Já com os homens, parece sempre querer que a consulta termine logo. Não investiga muito sobre sua vida, como vive a pessoa, parece realmente está preocupado com a queixa (PE2).

No contexto assistencial, esses discursos e práticas reproduzem valores hegemônicos que cristalizam necessidades sociais em saúde relacionadas ao exercício da sexualidade para os homens e ao exercício da reprodução para as mulheres e, deste modo, o acolhimento de tais necessidades de saúde pouco considera a dimensão relacional, dialógica e integral da assistência à saúde sexual e à saúde reprodutiva para homens e mulheres.

Os excertos a seguir, retirados da observação de grupos de planejamento familiar, ilustram a percepção de profissionais acerca da desarticulação entre mulheres e homens na discussão da reprodução e sexualidade e a dificuldade e/ ou despreparo que enfrentam diante da abordagem de tais questôes.

Em relação a usar ou não o preservativo, soubemos que há resistência de boa parte dos parceiros à investida das mulheres, geralmente incentivadas pelas enfermeiras a usarem o preservativo. Nesse sentido, uma das enfermeiras começou [a reunião do grupo de gestantes, na qual só havia mulheres] reforçando a necessidade do uso: "Vocês têm que usar a camisinha por vocês. Não importa se o parceiro não quer. Vocês têm que se cuidar". [...] Mais à frente, o discurso da palestra passou a apresentar conteúdos que consideravam essa problemática. A enfermeira disse: "Vocês têm que aprender a vestir [a camisinha], para quando o cara não quiser, vocês dizerem 'chegue, deixe eu botar para ver como fica', aí ele pode até deixar, vocês dão um jeitinho” (RN1).

Na reunião de planejamento familiar, a enfermeira fala que amanhã é o dia da luta contra Aids e lembra as mulheres (não havia homem na sala) que elas devem usar camisinha até com o marido, pois "[...] não se deve confiar plenamente neles, sendo a nossa vida-saúde coisa muito séria.” Após uma breve palestra [...], a enfermeira com a ajuda de uma ACS começa a chamar as mulheres, que dão as fichas de entrega dos anticoncepcionais e das camisinhas. Contabilizo umas 50 mulheres e, num determinado momento da distribuição dos preservativos e anticoncepcionais, a enfermeira fala bem alto em tom de graça: "Cadê os namorados e maridos de vocês que não vêm para o PSF, também só vou dar camisinha pros homens!” As mulheres acham graça! Uma das mulheres diz "Aí é que as doenças vão se agravar mesmo!", dando a entender que o papel de se cuidar é jogado para a mulher (PE2).

Podemos identificar, nesses excertos, uma desqualificação da participação dos homens nas decisões relacionadas à contracepção. Em vez de lançarem mão de estratégias para inclusão dos parceiros das usuárias nas atividades ou 
nas discussões sobre saúde reprodutiva, os/as profissionais reforçam, em seus discursos e práticas, a responsabilização das mulheres sobre a reprodução. Nesse sentido, os recursos que oferecem a elas não são direcionados para o horizonte de um diálogo bem informado com seus parceiros e de uma coparticipação na tomada de decisões. Ao contrário, parecem partir do pressuposto de que os homens não são capazes de atuar na promoção da saúde sexual e reprodutiva do casal, de forma que só restaria às parceiras recorrerem à imposição de sua escolha (quando a relação estabelecida lhes permite) ou à "negociação sexual" das práticas de cuidado.

Em relação às IST, as falas de médicos/as e enfermeiros/as indicam que eles/ as não destinam muita atenção ao problema, por perceberem que poucos casos chegam aos serviços. Já entre os/as ACS, que partilham com os/as usuários/as o cotidiano da comunidade, há a percepção de que esse é um problema frequente, especialmente entre os homens. Observamos algumas conversas em que o assunto dizia respeito a casos de IST em homens e à dificuldade destes em procurar os serviços de saúde. As distintas percepções não são confrontadas e tampouco dialogadas. A perspectiva apresentada pelos responsáveis pelo atendimento direto dos/as pacientes (médicos/as e enfermeiros/as) vai de encontro ao que o Ministério da Saúde aponta: as IST constituem um grave problema de saúde pública por sua magnitude, pela dificuldade das pessoas identificarem seus sintomas e, principalmente, por serem grandes facilitadores da transmissão do HIV (BRASIL, 2011a).

Consideramos ainda que a "pouca demanda" proveniente de IST, relatada por parte dos/as profissionais, possa estar atrelada à forma discrepante e "generificada" de acolher as necessidades de saúde de homens e mulheres no tocante a tais questões da saúde sexual. Nesse sentido, a afirmação de que há uma prevalência de IST em mulheres pode ser mais bem compreendida como fruto do direcionamento da atenção às usuárias, que contam com consultas e exames voltados ao diagnóstico precoce de tais problemas ou, em consequência das consultas de pré-natal e do controle ginecológico sobre a sexualidade feminina, são induzidas a essas atividades.

[O médico] informou que há uma demanda pequena em saúde sexual. Disse que a maioria dos casos são consultas individuais para tratar DST, especialmente vaginites e corrimentos. A maior parte da demanda emerge, na mesma proporção dos outros atendimentos, das mulheres. Descreveu o atendimento desses casos. "Tenho que fa- 
lar com um jeitinho que o marido precisa se tratar também, porque a maioria são mulheres casadas com parceiros fixos. Daí, se digo que elas pegaram do marido, vão pensar que ele tem outras [parceiras]. E nem sempre tem. Às vezes, ele tem a bactéria na forma sub-clínica. Daí ela se cura e pega de novo, é o que chamamos de infecção cruzada" (RN1).

Diferentemente das mulheres, os homens não contam com atendimentos voltados ao diagnóstico e tratamento desse problema de saúde. A detecção de IST neles precisa partir de sua própria iniciativa em procurar os serviços com esse fim ou de uma abordagem indireta dos/as profissionais tendo as parceiras como mediadoras. A prática dos/as profissionais, nesse sentido, reforça a invisibilidade dos casos de IST em homens.

Um rapaz entra, é bem jovem, negro, está descalço e com bermuda e blusa um pouco sujas. O médico pergunta o nome de sua ACS, ele fala que não lembra. Esse tipo de esquecimento parece irritar o médico, mas ele não fala nada e preenche os formulários. É a primeira vez que ele [usuário] vem ao posto. O médico pergunta qual a sua queixa, ele fala bem baixinho que está com uma coceira no pênis. $O$ médico pergunta se ele usa preservativo na relação, ele fala que não, fala que é casado. $\mathrm{O}$ médico pergunta se era uma ferida, ele fala que era uma ferida que coçava muito, mas que com o tempo sumiu e que hoje ficaram só as manchas. O médico pergunta se teve alguma doença venérea, doença de rua. Pergunta se ele já teve sífilis. Agora o paciente já fala alto sem constrangimento. O médico pergunta se a esposa dele se queixa de alguma coisa, ele fala que não e enfatiza que só tem relação com a esposa, não tem mulher na rua. O médico não dá muita atenção ao que o rapaz fala e diz que ele deveria ter vindo quando estava com a lesão e que agora fica difícil. O paciente parecia querer saber mais, mas o médico estava com pressa e muda de assunto dizendo que vai pedir um sumário de urina. O paciente pergunta onde isso vai ser feito, ele fala para se informar na recepção (PE1).

Adicionalmente, como podemos ver no excerto acima, a procura das unidades por parte dos homens, motivada por uma IST, parece ser tarefa que encontra resistência. A dificuldade destes em reconhecer problemas de saúde e de procurar o serviço de saúde para tratá-los, já assinalada na literatura (COURTENAY, 2000; COUTO et al., 2010), parece ser potencializada quando se trata de uma IST.

O pouco investimento para a inclusão dos homens no acompanhamento desses casos, assim como a percepção dos profissionais de que é baixa a incidência de IST nos homens, contrasta com a maior participação do sexo masculino nos perfis epidemiológicos referentes às IST (Gomes, 2008), sobretudo nos casos de HIV/aids (BRASIL, 2011b). 
Dado que o contexto assistencial deve ser tido como ambiente propício para o reconhecimento de necessidades de saúde que fogem à lógica organizacional instaurada nos serviços e na produção do trabalho, a investigação e o acompanhamento de IST, tanto em homens quanto em mulheres, se configuram como oportunidade de aproximação entre profissionais e usuários/as e de condução de um cuidado que ultrapasse a simples resolução da queixa apresentada.

Notamos que alguns/mas profissionais, diante da identificação de IST nas usuárias, dão-se conta da dimensão relacional da demanda. Ainda assim, a assistência prestada acaba por caminhar na direção de responsabilizar apenas a mulher, tomando-a como polo da relação a quem o cuidado parecer ser mais facilmente vinculado.

Outra enfermeira conta que, ao diagnosticar algum caso desses [IST] em uma usuária, deduz que o companheiro da mesma também esteja infectado. As usuárias são advertidas da necessidade da participação de seus maridos no tratamento; no entanto, alertam que eles se recusam a ir à unidade com esse fim. Dessa forma, o tratamento para o casal é orientado à mulher, que é incumbida de repassar para o companheiro. A enfermeira dificilmente tem informações a respeito da realização do tratamento pelo homem (RN1).

\section{A integralidade como horizonte na atenção à saúde sexual e à saúde reprodutiva na APS}

A integralidade, no contexto da prática assistencial dos serviços, aponta para a necessidade de uma (re)articulação entre sexualidade e reprodução que, ao invés de subjugar uma à outra, possibilite o reconhecimento das diversas expressões dessas esferas nas vivências concretas de homens e mulheres, assim como o diálogo entre diferentes questôes/intervençôes relacionadas à saúde sexual e à saúde reprodutiva a partir de pontos de convergência possíveis.

Essa articulação implica superar a naturalização presente tanto na conformação de políticas e serviços, como nos discursos e nas práticas dos profissionais de saúde. Nesse sentido, podemos identificar, no panorama traçado acima, a naturalização de uma imagem da mulher vinculada à relação conjugal e aos filhos, de forma que faz mais sentido aos/às profissionais preocupar-se com sua saúde reprodutiva do que com a saúde sexual. Sua sexualidade domesticada parece não demandar muita atenção. Ao contrário, o homem idealizado aparece como sujeito que não 
precisa ser escutado e acolhido. Sua sexualidade não precisa ser discutida, apenas controlada. Adicionalmente, parte-se da premissa de que ele não se interessa pela reprodução. Como observa Scott (2005), esse homem, que não é o "homem da família”, não é bem-vindo aos serviços de saúde.

Ambas as imagens são (re)produzidas na prática assistencial e pouco problematizadas, gerando resultados como a invisibilidade das demandas dos homens e o reforço da responsabilização das mulheres no tocante à saúde sexual e à saúde reprodutiva (MACHIN et al., 2011; FIGUEIREDO; SCHRAIBER, 2011). Não podemos esquecer que tal configuração não é de responsabilidade exclusiva dos/as profissionais de saúde, já que homens e mulheres enquanto usuários/as, ao responderem às conformações de padrões de masculinidade e feminilidade tradicionais, (re)produzem o imaginário social que distancia os homens das práticas de prevenção e promoção e prende as mulheres na responsabilidade do auto e hetero-cuidado.

A integralidade como princípio norteador de políticas públicas, da organização dos serviços, e das práticas de saúde (MATTOS, 2001) nos leva a considerar, em primeiro lugar, a relevância de políticas de saúde orientadas pela perspectiva de gênero, cuja proposição impulsiona e dá legitimidade à (re) organização das ações direcionadas à saúde de homens e mulheres, assim como à reflexão crítica sobre a atuação dos/as profissionais de saúde. Para tanto, a construção, a implantação e as atualizações dessas políticas devem seguir sempre na direção de compreensões mais abrangentes, contextualizadas e eticamente implicadas a respeito dos sujeitos a quem se destinam e das especificidades de suas demandas de saúde em função de gênero, sexualidade etc.

No âmbito dos serviços de saúde, isso implica criar espaços e proposições que contemplem a inclusão de diferentes demandas de homens e mulheres (para além dos modelos tradicionais e heteronormativos observados), assim como abordar a sexualidade e a reprodução como dimensōes da vida que se articulam nas experiências singulares das pessoas.

Em relação às práticas de saúde, a integralidade ainda exige a instauração de uma visão ampliada por parte dos/as profissionais em direção às diversidades de demandas, à superação das iniquidades e invisibilidades produzidas e ao estabelecimento de projetos terapêuticos orientados às singularidades que se apresentam, buscando-se a construção dialógica do cuidado (AYRES, 2004). 
Finalmente, fazemos a ressalva de que uma abordagem articulada entre homens e mulheres, assim como entre sexualidade e reprodução, não deve ser tomada como norma restritiva, no sentido de ser obrigatória às práticas de saúde. Isso iria de encontro à noção de integralidade. Ao contrário, a articulação apontada aqui deve ser encarada como horizonte no contexto de um cuidado integral. $\mathrm{Na}$ mesma direção, lembramos que tais dimensões não esgotam as possibilidades de integração da atenção em saúde, conforme têm mostrado as diferentes discussões em torno da integralidade. ${ }^{2}$

\section{Referências}

AQUINO, E. M.L. Saúde do homem: uma nova etapa da medicalização da sexualidade? Ciência e Saúde Coletiva. Rio de Janeiro, v.10, n.1, p.19-22, 2005.

AYRES, J.R.C.M. Cuidado e reconstrução das práticas de saúde. Interface - Comunic., Saúde, Educ. Botucatu, v.8, n.14, p.73-92, 2004.

AYRES, J.R.C.M. Para comprender el sentido práctico de las acciones de salud: contribuiciones de la hermenêutica filosófica. Salud Colectiva. Buenos Aires, v.4, n.2, p.159-72, 2008.

BRASIL. Ministério da Saúde. Secretaria de Atenção à Saúde. Departamento de Ações Programáticas Estratégicas. Política Nacional de Atenção Integral à Saúde da Mulher. Princípios e Diretrizes. Série C. Projetos, Programas e Relatórios. Brasília: DF, 2004.

BRASIL. Ministério da Saúde. Secretaria de Atenção à Saúde. Departamento de Atenção Básica. Política Nacional de Atenção Básica. Brasília: DAB/SAS/MS, 2006.

BRASIL. Ministério da Saúde, Secretaria de Atenção à Saúde, Departamento de Ações Programáticas Estratégicas. Política nacional de atenção integral à saúde do homem: princípios e diretrizes. Brasília: Ministério da Saúde, 2009. 79p.

BRASIL. Ministério da Saúde. Departamento de DST, Aids e Hepatites Virais. DST no Brasil. Disponível em: < http://www.aids.gov.br/pagina/dst-no-brasil >. Acesso em: 10 abr. 2011a.

BRASIL. Ministério da Saúde, Programa Nacional DST/Aids. Boletim Epidemiológico: Aids-DST [versão preliminar]. Brasília: Ministério da Saúde, $2011 \mathrm{~b}$.

CARRARA, S.; RUSSO, J.A.; FARO, L. A política de atenção à saúde do homem no Brasil: os paradoxos da medicalização do corpo masculino. Physis: Revista de Saúde Coletiva. Rio de Janeiro, v.19, n.3, p.659-678, 2009.

COURTENAY, W.H. Construction of masculinity and their influence on men's wellbeing: a theory of gender and health. Soc. Sci. Med. Amsterdam, v.50, n.10, p.1385-401, 2000.

COUTO, M.T. et al. O homem na atenção primária à saúde: discutindo (in)visibilidade a partir da perspectiva de gênero. Interface - Comunic., Saude, Educ. Botucatu, v.14, n.33, p.257-70, 2010. 
FIGUEIREDO, W.S.; SCHRAIBER, L.B. Concepções de gênero de homens usuários e profissionais de saúde de serviços de atenção primária e os possíveis impactos na saúde da população masculina, São Paulo, Brasil. Ciênc. saúde coletiva. Rio de Janeiro, v.16, supl.1, p.935-944, 2011.

FIGUEROA-PEREA, J.G. Algunos elementos para interpretar la presencia de los varones en los procesos de salud reproductiva. Cadernos de Saúde Pública. Rio de Janeiro, v.14, n.1, p.87-96, 1998.

GEERTZ, C. Do ponto de vista dos nativos. In: O saber local: novos ensaios de antropologia interpretativa. Petrópolis: Vozes, 1997. p.85-110.

GOMES, R. et al. Os homens não vêm! Ausência e/ou invisibilidade masculina na atenção primária. Ciên. e Saúde Coletiva. Rio de Janeiro, v.16, supl. 1, p.983-992, 2011.

GOMES, R. Sexualidade masculina, gênero e saúde. Rio de Janeiro: Fiocruz, 2008, 183p.

LAURENTI, R.; MELLO-JORGE, M.H.P.; GOTLIEB, S.L.D. Perfil epidemiológico da morbi-mortalidade masculina. Ciênc Saúde Coletiva. Rio de Janeiro, v.10, n.1, p.35-46, 2005.

LEAL, O.F.; BOFF, A.M. Insultos, queixas, sedução e sexualidade: fragmentos de identidade masculina em uma perspectiva relacional. In: PARKER, R.; BARBOSA, R. (Orgs.). Sexualidades brasileiras. Rio de Janeiro: Relume-Dumará,1996. p.119-35.

MACHIN, R. et al. Concepções de gênero, masculinidade e cuidados em saúde: estudo com profissionais de saúde da atenção primária. Ciênc. Saúde Coletiva. Rio de Janeiro, n.16, v.11, p.4503-4512, 2011.

MATTOS, R.A. Integralidade e a formulação de políticas específicas de saúde. In: PINHEIRO, R.; MATTOS, R.A. (Orgs.). Construção da integralidade: cotidiano, saberes e práticas em saúde. Rio de Janeiro: Cepesc, 2003. p.45-59.

MATTOS, R.A. Os sentidos da integralidade: algumas reflexões acerca de valores que merecem ser defendidos. In: PINHEIRO, R.; MATTOS, R.A. (Orgs.). Os sentidos da integralidade na atenção e no cuidado à saúde. Rio de Janeiro: Cepesc, 2001. p.39-64.

MEDEIROS, P.L.; GUARESCHI, N.M. de F. Políticas públicas de saúde da mulher: a integralidade em questão. Revista Estudos Feministas. Florianópolis, v.17, n.1, p.31-47, 2009. MEDRADO, B. et al. A construção de uma política nacional de atenção integral à saúde do homem. IN: TRINDADE, Z.A.; MENANDRO, M.C.S.; NASCIMENTO, C.R.R. (Orgs.). Masculinidades e práticas de saúde. Vitória: GM Editora, 2011. p.27-35.

MERHY, E.E. O ato de cuidar: a alma dos serviços de saúde. In: BRASIL. Ministério da Saúde. Secretaria de Gestão do Trabalho e da Educação na Saúde. Departamento de Gestão da Educação na Saúde. Rev - SUS Brasil: cadernos de textos. Brasília: Ministério da Saúde, 2004, p.108-137. 
PINHEIRO, T.F.; COUTO, M.T. Homens e camisinha: possibilidades e limites na construção da Saúde do Homem. Boletim do Instituto de Saúde. São Paulo, v.14, n.1, p.49-55, 2012.

ROHDEN, F. Uma ciência da diferença: sexo e gênero na medicina da mulher. Rio de Janeiro: Fiocruz, 2001, 222p.

SCHRAIBER, L.B. Equidade de gênero e saúde: o cotidiano das práticas do Programa de Saúde da Família do Recife. In: VILLELA, W.; MONTEIRO, S. (Orgs.). Gênero e saúde: Programa Saúde da Família em questão. Rio de Janeiro: Abrasco, 2005, p.30-61.

SCHRAIBER, L.B. Saúde dos homens... e mulheres: questôes de gênero na saúde coletiva [prefácio]. In: GOMES R. Sexualidade masculina, gênero e saúde. Rio de Janeiro: Fiocruz, 2008. p.7-20.

SCOTT, J.W. Gender: a useful category of historical analysis. The American Historical Review, v.91, n.5, p.1053-1075, 1986.

TEIXEIRA, R. O acolhimento num serviço de saúde entendido como uma rede de conversações. In: PINHEIRO, R.; MATTOS, R.A. (Orgs.). Construção da Integralidade: cotidiano, saberes e práticas em saúde. Rio de Janeiro: Cepesc, 2003. p.89-111.

VIEIRA, E.M. A medicalização do corpo feminino. Rio de Janeiro: Fiocruz, 2002, 81p.

VILLELA, W.; ARILHA, M. Sexualidade, gênero e direitos sexuais e reprodutivos. In: BERQUÓ, E. (Org.). Sexo e vida: panorama da saúde reprodutiva no Brasil. Campinas: UNICAMP, 2003. p.95-150.

\section{Notas}

${ }^{1}$ Pesquisa aprovada pelo Comitê Nacional de Ética em Pesquisa (Processo n. 0032/07).

${ }^{2}$ M.T.Couto coordenou a pesquisa da qual este artigo deriva. T.F.Pinheiro atuou como pesquisador de campo e desenvolveu parte da presente reflexão em sua dissertação de mestrado, sob orientação de M.T.Couto. Ambos trabalharam juntos na redação do artigo. 


\section{Abstract}

\section{Sexuality and reproduction: discussing gender and integral care in Primary Health Care} The notion of integral care, established as a principle for actions and policies in the Brazilian Unified Health System (SUS), has guided various discussions in the field of Collective Health. Following the direction of the debate on comprehensiveness-gender, this paper explores the (dis)articulation between sexuality and reproduction in the assistance provided to women and men in facilities of Primary Health Care (PHC). To that end, it makes a double appropriation of the idea of relationship, regarding men-women and sexuality-reproduction as inherently relational. This study is part of a multicentered qualitative survey conducted to investigate the relationship between men and PHC facilities. It uses data from ethnographic observation of four Family Health Units, located in the Brazilian states of Rio Grande do Norte and Pernambuco. The results point to disarticulations in the organizational structure of the facilities, which compromise the effectuation of an integral health care for men and women. Accordingly, the discourses and practices of health professionals (re) produce fragmentations in the assistance, especially on the basis of the association men-sexuality and women-reproduction. Taking the comprehensiveness as a horizon, it points to the need for a (re)articulation between sexuality and reproduction that, instead of subordinating one to another, allows the recognition of the various expressions of those spheres in concrete experiences of men and women, as well as the dialogue between different interventions related to sexual health and reproductive health starting from the possible points of convergence.

> Key words: comprehensive health care; reproductive health; sexuality; primary health care, gender. 